\title{
MONITORING THE RATE OF EXPANSION OF AGRICULTURAL FIELDS IN MWEKERA FOREST RESERVE USING REMOTE SENSING AND GIS
}

\author{
K. Kanja ${ }^{1,}$, M. Mwemba ${ }^{1}$, K. Malunga ${ }^{2}$ \\ ${ }^{1}$ KMU, Dept. of Agriculture and Aquatic Sciences, 480195, Chinsali, Zambia - (kennedy.kanja, malawo.mweemba)@cbu.ac.zm) \\ ${ }^{2}$ Zambia Forestry College, Kitwe, Zambia - kangulwe_malunga@yahoo.com
}

Commission III, WG III/10

KEY WORDS: Remote Sensing and GIS, Land Cover Change, Landsat TM and ETM+, Mwekera forest reserve

\begin{abstract}
:
Rapid population growth and rural-urban migration amidst limited job opportunities lead to conversion of land from forests into agriculture and other land uses. In this study, Zambia's Mwekera national forest reserve was used as a case study to assess the rate of expansion of agricultural fields using remote sensing and GIS. Iterative Self-Organizing Data Analysis Technique (ISODATA) as well as maximum likelihood supervised classification on four Landsat images as well as accuracy assessment of the classifications was performed. . Over the period under observation, results indicate annual percentage changes to be $-0.03,-0.49$ and 1.26 for agriculture, forests and settlement respectively indicating a higher conversion of forests into human settlements and agriculture.
\end{abstract}

\section{INTRODUCTION}

Zambia is faced with population increase over the next several decades, with this increase in population the Zambian agriculture sector will require large and sustained growth in production. Some of this growth in production will need to come from yield improvements, and most certainly, it is expected that this growth in production will largely depend on land expansion (Nicholas and Jordan, 2016). Zambia has a total surface area of $751,610 \mathrm{~km} 2$ and a population of 14.6 million people, it is reported that Zambia has the lowest population density in sub-Saharan Africa; therefore it is important to know the rate at which land which is so abundant is being converted into agricultural use (ZDA, 2014). Rapid population growth and rural- urban migration has had implications on how land is used, with subsequent impacts on natural vegetation cover, and food security. Clearing of natural vegetation may predominantly modify the vegetation cover and in turn have a long-term impact on sustainable food production, forest resources and climate change (Brink and Eva, 2009). It is important that the changes occurring in land use are accurately documented at time intervals. Such data will help in providing completeness on crop production data based on estimates. Accurate land use maps can be an effective tool that can help in management of land by aiding in deciding what sort of lands are capable of sustaining agriculture. Large amounts of data are required for developing such land use maps and remote sensing and GIS can be a tool for accurate detailed information over large areas over a period of time (Saadat et al., 2011). Land use classification is a widely used application in remote sensing, although there are several other methods approaches that have been used to correlate image data with vegetation characteristics.

This study aims to use Zambia's Mwekera national forest reserve to assess the rate of expansion of agricultural fields using remote sensing and GIS. The results will help in modelling the rate of forest conversion into agricultural fields.
Iterative Self-Organizing Data Analysis Technique (ISODATA) as well as maximum likelihood supervised classification on five

Landsat images (1998, 2003, 2008, 2013 and 2015) and accuracy assessment of the classifications was performed in ArcGIS.

\section{MATERIALS AND METHODS}

\subsection{Study area}

Zambia is located in Sub-Saharan Africa between latitudes 8 and 18 degrees south of the Equator and longitudes 22 and 34 degrees east of the Greenwich Meridian with a mean altitude of 1200 meters above sea level (Shitima, 2005).

Mwekera National Forest was established in 1946 through a statutory instrument number 72 of 3rd May, 1946 with an original size of 27,500 acres. The purpose of the reserve was the conservation of the forest, which formed a catchment area for Mwekera stream from which the name came. This stream drains into the more important Kafue River. The Mwekera stream also forms the catchment for the national aquaculture or fish farming centre, which is also located within the Mwekera National Forest (GRZ, 1965).

Mwekera just like most parts of Zambia is covered by the Miombo woodlands, open and closed forests. The most important species in these woodlands include Brachystegia, Julbernadia and Isorberlinia. Terminaria. This woodland vegetation covers about 3.23 percent and is present in all parts of the country. (GRZ, 2002).

\footnotetext{
* Corresponding author
} 


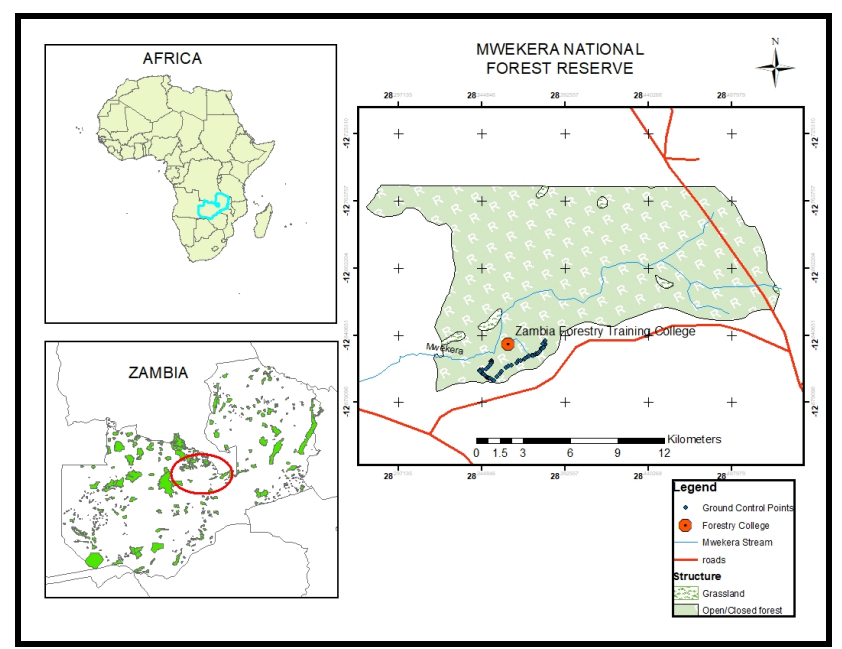

Figure 1. Study area map

\subsection{Ground truth data}

As total of 51 GPS points collected within the last two years were used as ground truth data. These points indicated land use type around that particular area indicating how long the field is in case of agriculture as well as the type of vegetation cover in the case of forest.

\subsection{Remote Sensing data}

Available Landsat 8 Operational Land Imager (OLI) as well as Landsat 4-5 TM images for 1998, 2003, 2008, 2013 and 2018 were downloaded from the USGS Earth Resources Observation and Science (EROS) Centre archive (Path/Row: 172/69). After stacking the bands for each period, clip images encompassing the entire mwekera forest reserve were used for land classification.

\subsection{Classification}

The stacked images were independently classified into 20 spectral classes using a statistical unsupervised clustering algorithm (ISODATA) and supervised maximum likelihood classification and then visually interpreted into the four main land cover classes of interest (settlements/bareland, forests, agricultural fields and water).

For change detection, a number of authors have preferred to opt for combined processing of the recent and historical data sets (Coppin et al, 2004; Lu, et al 2003). However, this study has challenges because it combined images captured using MMS, $\mathrm{TM}$ and ETM+ sensors. To compensate for this the image interpretation (i.e. class labelling) was carried out interdependently (i.e. assessing the classes of the historical and recent images at the same time). Expert knowledge, google earth as well as interpreter knowledge of the study area played a bigger role.

For classification of each of the five Landsat images, the study proceeded in four steps: (i) preprocessing of the images, (ii) extraction of study area (iii) unsupervised classification (iv) supervised classification. Upon completion of all these processes, the accuracy of the classifications was done for each imaging. Finally, the analysis of land use changes was done using ArchGIS and later fed into Microoft excel pivot table.

\subsubsection{Pre-processing}

Landsat images for the study area were geo-referenced. Landsat image bands that were of interest (bands 1-6 for TM and bands 2-7 for $\mathrm{ETM}+$ ) were stacked together into a multilayer image that was used during the classification.

\subsubsection{Extraction of the study area}

Using the image analysis tool in ArcGIS, the shapefile of Mwekera forest reserve and the five stacked multilayer images for the 20 year period under observation (1998-2018) were overlaid and then clipped so as to only remain with the multilayer images encompassing Mwekera forest reserve.

\subsubsection{Unsupervised classification}

For each of the clipped stacked Landsat images for 1998, 2004, 2008, 2013 and 2018, the Iterative Self-Organizing

Data Analysis Technique (ISODATA) was performed in ArcGIS. This is a type of unsupervised classification based on the natural groupings of pixels (Saadat et al, 2011). Based on this method, raw classified maps with 20 classes were obtained. These were then used in the supervised classification as aid in making training samples.

\subsubsection{Supervised classification}

Overlaying the original images; the 20 class classified images; the ground truth data as well as google maps; a maximum likelihood supervised classification was done. The resulting classified maps were used in the reclassification leading to land cover maps with only the four classes of interest namely agricultural fields, forests, settlements and water bodies using the spatial analyst tool.

The 4-5-class classified images were then converted into polygon shapefiles and GIS analysis was performed to as to assess the land cover changes.

\section{RESULTS AND DISCUSSION}

\subsection{Results}

After going through all the steps outlined in 2.4 above, the results indicated various landcover changes as outlined below. The accuracy of the classification had overall accuracy ranging from $70 \%$ to $80 \%$ with Kappa ranging from $65 \%$ to $75 \%$. 


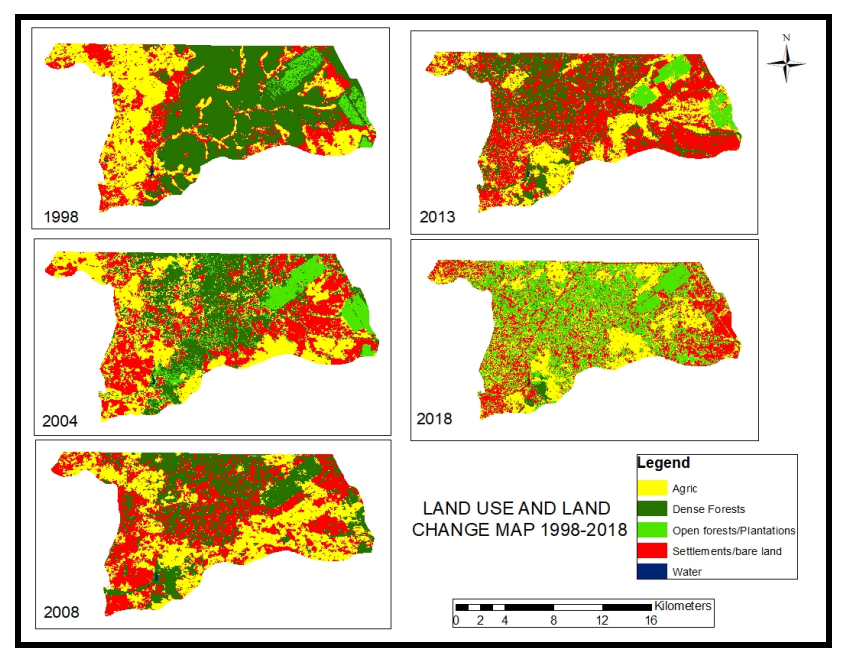

Figure 2. Land Cover Map

\subsubsection{Land cover changes between 1998 and 2004}

The results reveal that over this 6-year period agriculture has increased by $0.1 \%$ from 5,981 hectares to 5,986 hectares while forest cover has reduced by $20 \%$ from 9,406 hectares to 7,509 hectares. (Table 1). This reduction in forest cover was because of expansions of agricultural fields and human settlements, which increased respectively by $0.1 \%$ and $47 \%$.

\begin{tabular}{|l|l|l|l|l|}
\hline \multirow{2}{*}{ Land use } & \multicolumn{4}{|c|}{ Areas in hectares (ha) } \\
\cline { 2 - 5 } & 1998 & 2004 & $\begin{array}{l}\text { Change } \\
\text { (ha) }\end{array}$ & $\begin{array}{l}\text { Change } \\
(\%)\end{array}$ \\
\hline Agric Fields & 5980.7 & 5985.5 & 4.8 & 0.1 \\
Forests & 9405.9 & 7509.4 & -1896.5 & -20 \\
$\begin{array}{l}\text { Settlements/BareLan } \\
\text { d }\end{array}$ & 4246.5 & 6254.4 & 2007.9 & 47 \\
Water Bodies & 12.8 & 12.2 & -0.6 & -4.6 \\
\hline
\end{tabular}

Table 1. Land cover change 1998-2004

\subsubsection{Land cover changes between 2004 and 2008}

There was a reduction again during this period in forest cover by $20 \%$ from 7509.4 hectares to 6002.5 hectares. Out of this forest cover loss, 1145.6 converted into agriculture and 484.7 ha into settlements/bare land. Over all, settlements/bare land and agricultural fields which increased by $20.5 \%$ and $3.7 \%$ respectively.

\begin{tabular}{|l|l|l|l|l|}
\hline \multirow{2}{*}{ Land use } & \multicolumn{4}{|l|}{ Areas in hectares (ha) } \\
\cline { 2 - 5 } & 2004 & 2008 & $\begin{array}{l}\text { Change } \\
\text { (ha) }\end{array}$ & $\begin{array}{l}\text { Change } \\
(\%)\end{array}$ \\
\hline Agric Fields & 5985.5 & $\mathbf{6 2 0 8 . 9}$ & 223.4 & 3.7 \\
Forests & 7509.4 & $\mathbf{6 0 0 2 . 5}$ & -1506.9 & -20 \\
Settlements/BareLan & 6254.4 & $\mathbf{7 5 3 5 . 2}$ & 1280.8 & 20.5 \\
d & & & & \\
Water Bodies & 12.2 & $\mathbf{1 5 . 3}$ & 3.1 & 2.5 \\
\hline
\end{tabular}

Table 2. Land cover change 2004-2008

\subsubsection{Land cover changes between 2008 and 2013}

Major land cover changes between 2008 and 2013 saw a reduction in agriculture fields by $25 \%$ from 6,209 hectares to 4,649 hectares. Of this this agriculture land conversion, about 1500 ha became settlements/bare land while about 700ha became reverted to forest. In percentages, human settlements/bareland and forests increased by $18.7 \%$ and $2.4 \%$ respectively.

\begin{tabular}{|l|l|l|l|l|}
\hline \multirow{2}{*}{ Land use } & \multicolumn{4}{|c|}{ Areas in hactres (ha) } \\
\cline { 2 - 5 } & 2008 & 2013 & $\begin{array}{l}\text { Change } \\
\text { (ha) }\end{array}$ & $\begin{array}{l}\text { Change } \\
(\%)\end{array}$ \\
\hline Agric Fields & 6208.9 & $\mathbf{4 6 4 8 . 8}$ & -1560.1 & -25 \\
Forests & 6002.5 & $\mathbf{6 1 5 1 . 0}$ & 148.5 & 2.4 \\
Settlements/BareLan & 7535.2 & $\mathbf{8 9 4 8 . 0}$ & 1412.8 & 18.7 \\
d & & & & \\
Water Bodies & 15.3 & $\mathbf{9 . 9}$ & -5.4 & 3.5 \\
\hline
\end{tabular}

Table 3. Land cover change 2008-2013

\subsubsection{Land cover changes between 2013 and 2018}

The results between 2013 and 2018 indicate an increment of $27.5 \%$ in agriculture from 4,648 hectares to 5,929 hectares. About 1100 ha of forests was converted into agriculture as well as about 2500ha of settlements/bare land. Forests overall indicated a tremendous increase of $34 \%$ while settlements/bareland showed a decrease of $37.6 \%$.

\begin{tabular}{|l|l|l|l|l|}
\hline \multirow{2}{*}{ Land use } & \multicolumn{4}{|l|}{ Areas in hactres (ha) } \\
\cline { 2 - 5 } & 2013 & 2018 & $\begin{array}{l}\text { Change } \\
\text { (ha) }\end{array}$ & $\begin{array}{l}\text { Change } \\
\text { (\%) }\end{array}$ \\
\hline Agric Fields & 4648.8 & $\mathbf{5 9 2 9 . 5}$ & 1280.8 & 27.5 \\
Forests & 6151 & $\mathbf{8 2 5 2 . 4}$ & 2101.4 & 34 \\
$\begin{array}{l}\text { Settlements/BareLan } \\
\text { d }\end{array}$ & 8948.0 & $\mathbf{5 5 8 2 . 2}$ & 3365.8 & -37.6 \\
Water Bodies & 9.9 & $\mathbf{5 . 1}$ & -4.8 & -48.5 \\
\hline
\end{tabular}

Table 4. Land cover change 2013-2018

\subsection{Discussion}

Using remote sensing and GIS, this study tried to report on the rates of agriculture expansion in Mwekera national forest reserve between 1998 and 2018. As of the year 1998, the estimates from Landsat image analysis indicated that about 30\% of land cover for Mwekera was agriculture, $48 \%$ forest and $22 \%$ settlements and/or bare land. Over the period under observation, this study reported annual percentage changes to be $-0.03,-0.49$ and 1.26 for agriculture, forests and settlement respectively indicating a higher conversion of forests into human settlements.

These annual percentage changes concur with that of Andreas and Eva (2009) whose results for sub-Saharan (bwtween 19752000) indicated $2.3,-0.7$ and -0.62 .3 for agriculture, forest and barren respectively.

Despite being done on a very small scale as compared to the other studies, results of this study clearly indicate a reduction in forest cover while agriculture and settlement were on the rise (Figure 3). 


\section{Land Cover Change 1998-2018}

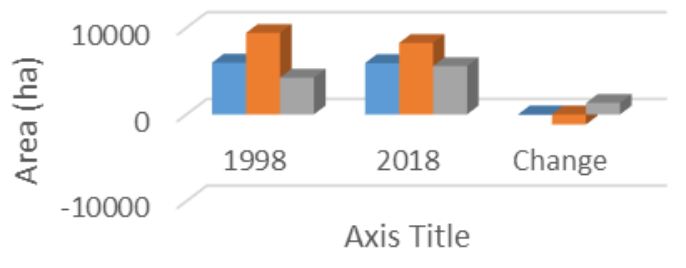

agric $\square$ forests $\square$ settlements
Lu, D., Mausel, P., Brondízio, E., Moran, E., 2004. Change detection techniques. International Journal of Remote Sensing, 25:12, pp. 2365 2401, DOI: $10.1080 / 0143116031000139863$

Saadat, H., Adamowski, J., Bonnell, R., Sharifi, F., Namdar, M., Ale-Ebrahim, S., 2011. Land use and land cover classification over a large area in Iran based on single date analysis of satellite imagery, ISPRS Journal of Photogrammetry and Remote Sensing 66 (2011) pp. 608-619.

Shitima, E.M., 2005. Forest Conservation and People's Livelihoods: Explaining Encroachment on Zambia's Protected Forest Landscapes -The Case Of Mwekera National Forest, Kitwe, Copperbelt, Masters Thesis, Norwegian University of Science and Technology (NTNU), Trondheim, Norway, https://core.ac.uk/download/pdf/30817658.pdf

Sitko, Nicholas \& Chamberlin, Jordan, 2016. The geography of Zambia's customary land: Assessing the prospects for smallholder development. Land Use Policy. 55. 49-60. 10.1016/j.landusepol.2016.03.026

Zambian Development Agency, 2014. Agriculture Sector Pamphlet Government of Zambia, Lusaka, Zambia. Accessed online March 15th 2015 at: http://www.

zda.org.zm/sites/default/files/Agriculture\%20Sector\%20Leaflet $\% 20-\% 202014$ 0. Pdf

This study aimed at monitoring the rate of expansion of agriculture in Mwekera Forst reserve using Remote Sensing and GIS. We can conclude by saying that despite not having a vast sample size of ground truth data, the rate of encroachments in the forest reserve by way of settlements and agriculture was successfully assessed using Remote Sensing and GIS going by the accuracy assessment results as well as comparing with rsluts of similar studies. Therefore, Remote sensing and GIS technologies can play a key role as a decision support tool when it comes to monitoring agriculture expansion remotely.

\section{REFERENCES}

Brink, A. B., Eva, H.E., 2009. Monitoring 25 years of land cover change dynamics in Africa: A sample based remote sensing approach. Applied Geography 29 (2009), pp. 501-512

Coppin, P., Jonckheere, I., Nackaerts, K., Muys, B., 2004. Digital change detection methods in ecosystem monitoring: a review. Int. J. Remote Sensing, Vol. 25, No. 9, pp. 1565-1596

GRZ, 1965. Forest Ordinance, Forest Department, Lusaka, Government Printers

GRZ, 2002. The Poverty Reduction Strategy Paper (PRSP), Ministry of Finance and National Planning (MoFED), Lusaka, Government Printers

Kanja, K., Malawo, M., Siwale, W., 2017. Time series analysis of encroachments in Mwekera forest reserve using Remote Sensing and GIS. The International Journal of Multi-

Disciplinary Research ISSN: pp. 3471-7102 